\title{
Reactions of College Students to the Sexuality of Older People
}

\author{
Emily Waterman $^{\mathrm{a}}$
}

The reactions of 153 college students to incidents of sexuality were measured using a series of scenarios. Age of target was manipulated with three levels (30-35, 50-55, and 70-75) to test reactions to the sexuality of different age groups. Gender of target was also manipulated with three levels (female, male, and couple). For sexual scenarios, age of target was found statistically significant for all reactions, with responses less favorable toward older targets. No gender differences were found for sexual scenarios. Results were evidence for a strong bias against the sexuality of older people.

Keywords: Aging, Sexuality, Biases, Ageism

\section{Introduction}

In Western society, perceptions and visibility of sexuality have changed dramatically; our society has become more permissive of the sexuality of teenagers, single adults, unmarried couples, homosexuals, and many other groups (Hodson \& Skeen, 1994). The sexuality of these groups has become highly evident. It seems that the elderly, however, have been largely kept out of this new-found permissiveness and visibility. The elderly are often seen as asexual: too old or sick to partake in sexual activity. However, there are many factors that make aging and sexuality a salient issue. First, people are living longer, and the population of people over 65 is growing rapidly. Older people are becoming more visible, and more active in society. The "baby boomer" generation, responsible for the sexual revolution of the 1960s and 1970s, will likely demand a certain standard for quality of life, which will include an active sex life. The second factor is that an active sex has become recognized as part of a quality life. Lastly, the increased availability and use of medications that aid sexual activity, such as treatments for erectile dysfunction and hormone replacement, have given attention to the sexuality of older people (Yee, 2010).

The views on the sexuality of elders are part of a larger, ageist view on the old in society. Ageism is discrimination or prejudice based on age. Ageism is not overt and usually not meant to harm; people naturally categorize information to form opinions on people and make quick decisions on how to treat others (Hillier \& Barrow, 2007). Ageism in the realm of sexuality is perpetuated by the media: the media rarely shows older people in the role of sexual beings, and constantly associates sexual attractiveness with youth. Signs of aging, such as wrinkles, weight gain, or graying hair are seen as unattractive. As people grow and age, they are surrounded by these messages. We take in attitudes, culture, and images we see, and use them to construct not only our expectations for others, but for ourselves (Deacon, Minichiello, \& Plummer, 1995; Delamater \& Still, 2005; Hillier \& Barrow, 2007). Unfortunately, cultural beliefs are often internalized, so that people expect that they will no longer be sexually attractive or active into their old age, and therefore are not. Although one cannot deny the effects of certain physiological changes that occur with age, those effects are often exaggerated; the psychological aspects are more influential to the continuation of a healthy sex life into old age (Hall, Selby, \& Vanclay, 1982).

As stated above, ageism is usually not deliberate. However, there are many negative consequences to invisibility of sexuality in older people. According to Hillier \& Barrow (2007), sexuality in older people is seen with condescension ("cute"), with humor, or with shock and disdain. No one wants to elicit these responses from people when addressing personal matters, so older people are more likely to keep their sexuality hidden from people. Keeping sexuality hidden can be harmful when problems arise. Most older people feel awkward bringing up a sexuality issue to their doctors, for fear of getting the responses above, but hope their doctors will bring them up. In one study, physicians who asked older patients about sexual problems during a routine exam were twice as likely to find a sexual problem as those who only asked about sex when problems were obvious or patients brought them up (Hodson \& Skeen, 1994). A second reason for the importance of this issue is that the research shows that a healthy sex life in old age greatly contributes to happiness and quality of life. Kaplan (1990) states that premature loss of sexual functioning can contribute to emotional and physical deterioration in people; hanging onto sexuality can lessen feelings of loss in old age and increase self-esteem. Similarly, Kontula \& Haavio-Mannila (2009) state that aging women who have a partner and enjoy intimacy are in better mental health than those who do not.

If it is possible that the views of younger people on the sexuality of older people have these negative effects, then it is necessary to research those attitudes of younger people. Although there is not a huge body of research in this area, there are several studies, which have yielded mixed results. Pratt \& Schmall (1989) instructed students in a human sexuality class to rate sexual scenarios that varied targets' age, gender, and relationship to the respondent. Surprisingly, no significant difference was found in age of target in the scenario. However, respondents did not rate positively those incidents of sexuality where the target in the scenario was described as close to them, such as a grandparent. A weakness of this study is that it tested students who had chosen to enroll in a human sexuality class; such students might be more knowledgeable and tolerant than other students. The present research looks to eliminate this 
weakness by using general psychology students. LaTorre (1977) found when participants rated sexual stories with different aged actors, the stories were found less credible and less moral when the character in the story was old, compared to young characters. In this study, the only behaviors assessed were masturbation and intercourse. The present study attempts to gage respondents' feelings toward a range of sexual behaviors.

The present study will also explore the presence of a double standard in sexual attitudes for men and women. According to Lai (2011), a standard is the expectation for behavior that people must follow or be viewed negatively. In regards to sexuality, men and women are judged much differently for the same behavior. Along with the sexual double standard, there is a discrepancy in the expectations for male behavior and female behavior, based on gendered stereotypes. Men are expected to always want sex and be willing to engage in sexual activity at any point, where females are expected to consider sex a part of a committed, loving relationship, and only want sex when it will further this relationship. Although society's overall view on sex is becoming more permissive for both genders, this double standard, along with stereotypes based on gender, still remains.

According to Lai's research in Canada, participants' views were consistent with the hypothesis: their attitudes were least permissive for older females and most permissive for younger males. Overall, older people were perceived by respondents to be less interested in sex than younger people. Females were perceived to be more interested in traditional sex (kissing and sex with commitment), where males were perceived to be more interested in experimental sex (sex outside, viewing erotica, group sex, partners with a large age difference). The present study hopes to replicate these results, with response to scenarios instead of surveying perceptions of others' sexual interest.

The current study will consist of ten scenarios, seven of which have sexual content, that will place the respondent in a situation of observing sexual content and ask them to rate their feelings of surprise, disgust, and acceptability and appropriateness of the behavior in the scenario. There will also be three nonsexual scenarios, which depict situations that will be unusual of older people: hiking, getting a tattoo, and driving a motorcycle across country. The age of the character in the story is manipulated (30s, 50s, 70s) as well as the gender and couple status (single female, single male, couple). The purpose is to test the reactions of college-age students on the sexuality of older adult compared to younger adults. The study will also test for the presence of a double standard, by comparing females to males to those in a committed relationship. The hypothesis of this research is that respondents will feel most negatively towards scenarios depicting an old female, and most positively toward scenarios depicting young males.

\section{Method}

\section{Participants}

This study tested students in the introduction to psychology course at Siena College. Participants were given research participation credit in partial fulfillment of a course requirement. Subjects were randomly assigned to a condition. There were a total of 153 participants. Subjects were college students, aged 17-21. A total of 53 men and 100 women participated in the study.

\section{Materials}

A total of ten scenarios, created by the researcher, were used (see Appendix A). Seven scenarios contained sexual content and three did not. An example of a sexual content scenario is as follows: "You are shopping in the video rental store. You overhear a woman in her early 70s asking a clerk where she could find an adult section with X-rated videos." An example of a scenario without sexual content is: "A friend asks you to accompany her while she gets a tattoo. While waiting in the tattoo parlor, you see a woman who is 70 to 75 years old getting a tattoo on the back of her shoulder." The wording of the scenarios was changed to manipulate two variables. To reflect variable one, age, the age of the target in the scenarios was changed depending on condition: 30-35, 50-55, and 70-75. Variable two, gender and couple status, also had three levels: single male, single female, and couple. Each group of scenarios depicted this variable as a condition of the target. For the couple condition, the scenarios depicted a man and woman together. There were nine conditions total.

\section{Procedure}

Participants were told the study would require them to rate their feelings on the activities in scenarios, in order to gather research on the behaviors depicted. They were not told that age, gender, and couple status of the target in the scenarios was manipulated. After consenting to participate, subjects were given a packet that contained ten scenarios. Following reading a scenario, participants were asked to rate their levels of surprise and disgust from one to seven. They were also asked to rate from one to seven how acceptable and appropriate they found the behavior in the scenario (see Appendix B).

\section{Results}

For the purposes of analysis, the responses for all sexual scenarios were separated from the nonsexual scenarios. A mean score for each respondent was used for each of the four reactions. In each case a 3(age) by 3(gender) between-groups analyses of variance was used. Significant main effects were examined using a Tukey's HSD test with the alpha level of 0.05 . Eight analyses were done in total, examining the four reactions for sexual scenarios, and four reactions for nonsexual scenarios.

\section{Sexual Scenarios}

For the reaction of surprise for the sexual scenarios, there was a significant main effect for age, $\mathrm{F}(2,144)=29.68$, $\mathrm{p}<$ 0.001 . The Tukey's HSD test revealed that the early adulthood condition $(\mathrm{M}=4.25, \mathrm{SD}=1.14)$ reported significantly less surprise than the middle adulthood condition $(\mathrm{M}=5.03, \mathrm{SD}=$ $0.98)$, which in turn was less than the late adulthood condition $(\mathrm{M}=5.79, \mathrm{SD}=0.93)$. There was no significant main effect for gender, $\mathrm{F}(2,144)=1.79, \mathrm{p}=0.17$. There was no interaction, $\mathrm{F}(4$, 144) $=1.14, \mathrm{p}=0.34$.

For the reaction of disgust for the sexual scenarios, there was a significant main effect for age, $\mathrm{F}(2,144)=14.74$, $\mathrm{p}<$ 0.001. A Tukey's HSD test showed that the early adulthood condition $(\mathrm{M}=3.41, \mathrm{SD}=1.1)$ reported significantly less disgust than the middle adulthood condition $(\mathrm{M}=4.18, \mathrm{SD}=$ $1.2)$ and the late adulthood condition $(\mathrm{M}=4.65, \mathrm{SD}=1.18)$. The middle and late adulthood conditions did not differ significantly. There was no significant main effect for gender, $\mathrm{F}(2,144)=$ 
0.329, $\mathrm{p}=0.72$. There was no interaction, $\mathrm{F}(4,144)=1.58, \mathrm{p}=$ 0.18 .

When asked how acceptable a situation was, participants' responses revealed a significant main effect for age, $\mathrm{F}(2,144)=$ 4.87, $\mathrm{p}=0.009$. A Tukey's HSD test showed that the late adulthood condition $(\mathrm{M}=4.15, \mathrm{SD}=1.04)$ differed significantly from the early adulthood condition $(\mathrm{M}=4.71, \mathrm{SD}=1.01)$ and the middle adulthood condition $(\mathrm{M}=4.65, \mathrm{SD}=0.88)$. Participants found the situations less acceptable if they contained targets in late adulthood than if they contained targets in middle adulthood or early adulthood. The early and middle adulthood conditions did not differ significantly. There was no significant main effect for gender, $\mathrm{F}(2,144)=1.430, \mathrm{p}=0.024$, and there was no interaction, $\mathrm{F}(4,144)=0.43, \mathrm{p}=0.79$.

When asked how appropriate a situation was, participants' responses showed a significant main effect for age, $\mathrm{F}(2,144)=$ 4.7, $\mathrm{p}=0.01$. A Tukey's HSD test showed that the late adulthood condition $(\mathrm{M}=4.02, \mathrm{SD}=1.02)$ was rated significantly less appropriate then the early adulthood condition $(\mathrm{M}=4.55, \mathrm{SD}=1.03)$ and the middle adulthood condition $(\mathrm{M}=$ $4.52, \mathrm{SD}=0.9$ ). The early and middle adulthood conditions did not differ significantly. There was no significant main effect for gender, $\mathrm{F}(2,144)=2.2, \mathrm{p}=0.12$, and there was no interaction, $\mathrm{F}(4,144)=1.02, \mathrm{p}=0.4$.

Table 1. Sexual Scenarios

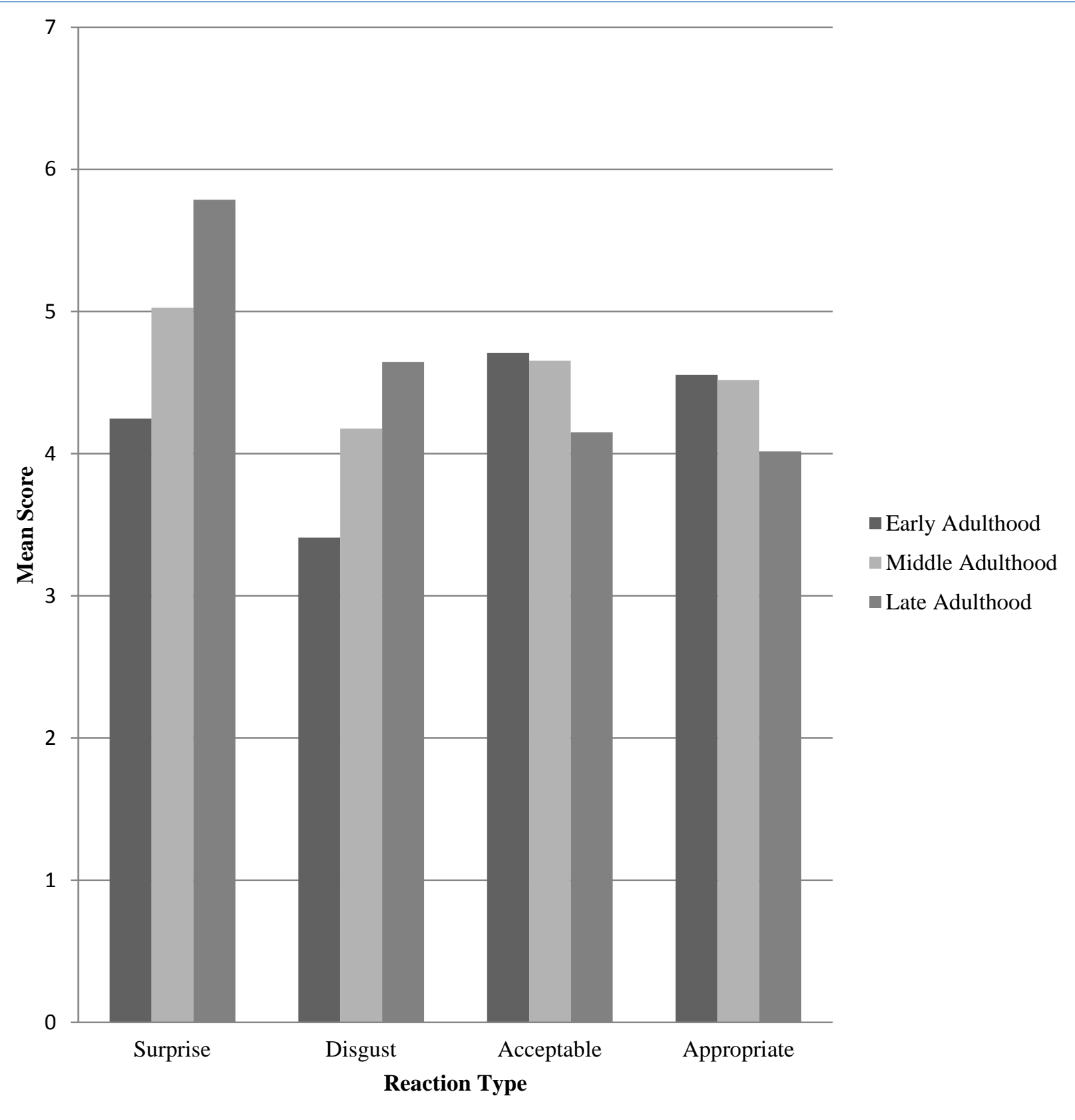




\section{Nonsexual Scenarios}

For the reaction of surprise in the nonsexual scenarios, there was a main effect for age, $\mathrm{F}(2,144)=10.22$, $\mathrm{p}<0.001$. A Tukey's HSD test revealed that the late adulthood condition (M $=4.68, \mathrm{SD}=1.37)$ differed significantly from the early adulthood $(\mathrm{M}=3.05, \mathrm{SD}=1.15)$ and the middle adulthood condition $(\mathrm{M}=3.78, \mathrm{SD}=2.7)$. Participants were more surprised by the late adulthood condition than the early and middle adulthood conditions; no significant difference was found between early and middle adulthood. There was no significant main effect for gender, $\mathrm{F}(2,144)=1.3, \mathrm{p}=0.28$, and there was no interaction, $\mathrm{F}(4,144)=2.16, \mathrm{p}=0.08$.

For the reaction of disgust for the nonsexual scenarios, there were no significant main effects for age, F 2,144) $=0.29$, p = 0.75 . There were no significant main effects for gender, $\mathrm{F}(2,144)=2.22, \mathrm{p}=0.11$. There was no interaction, $\mathrm{F}(4,144)=$ $0.74, \mathrm{p}=0.57$.

When asked how acceptable a scenario was, participants' responses yielded a significant main effect for age, $\mathrm{F}(2,144)=$ $5.59, \mathrm{p}=0.005$. A Tukey's HSD test revealed that the late adulthood condition $(\mathrm{M}=5.33, \mathrm{SD}=1.07)$ were rated as less acceptable than the early adulthood condition $(\mathrm{M}=5.88, \mathrm{SD}=$ $0.94)$ and the middle adulthood condition $(\mathrm{M}=5.94, \mathrm{SD}=$ 0.89 ). The early and middle adulthood conditions did not differ significantly from each other. There was also a main effect for gender, $\mathrm{F}(2,144)=5.28, \mathrm{p}=0.008$. For gender, a Tukey's HSD test revealed a significant difference between the female condition $(\mathrm{M}=5.46, \mathrm{SD}=1.13)$ and the couple condition $(\mathrm{M}=$ $6.07, \mathrm{SD}=0.89$ ), with the couple condition being more acceptable than the female condition. A marginal difference $(\mathrm{p}=$ 0.07) was found between the couple condition and the male condition $(\mathrm{M}=5.61, \mathrm{SD}=1.09)$, with the couple condition being more acceptable. There was no significant difference between the female and male conditions. There was no interaction, $F(4,144)=0.07, p=0.99$.

When asked how appropriate a scenario was, participants' responses yielded a significant main effect for age, $\mathrm{F}(2,144)=$ $3.59, \mathrm{p}=0.03$. A Tukey's HSD test found marginal differences $(\mathrm{p}=0.058)$ between the early adulthood $(\mathrm{M}=5.86, \mathrm{SD}=1.03)$ and the late adulthood condition $(\mathrm{M}=5.38, \mathrm{SD}=1.09)$, the early adulthood condition being more appropriate. There were negligible differences $(\mathrm{p}=0.06)$ between the middle adulthood condition $(\mathrm{M}=5.95, \mathrm{SD}=1.0)$, and the late adulthood condition, the middle adulthood condition being rated as more appropriate. There were no differences between the early and middle adulthood conditions. There was also a main effect of gender, $F(2,144)=4.03, p=0.02$. The Tukey's HSD test showed that participants rated situations with a female target (M $=5.4, \mathrm{SD}=1.16)$ as significantly less appropriate than those with a couple as the target $(\mathrm{M}=5.99, \mathrm{SD}=0.9)$. There was no difference between the male condition $(\mathrm{M}=5.67, \mathrm{SD}=1.04)$ and the female condition, nor the male and couple condition. There was no interaction, $\mathrm{F}(4,144)=0.35, \mathrm{p}=0.84$.

Table 2. Non-Sexual Scenarios

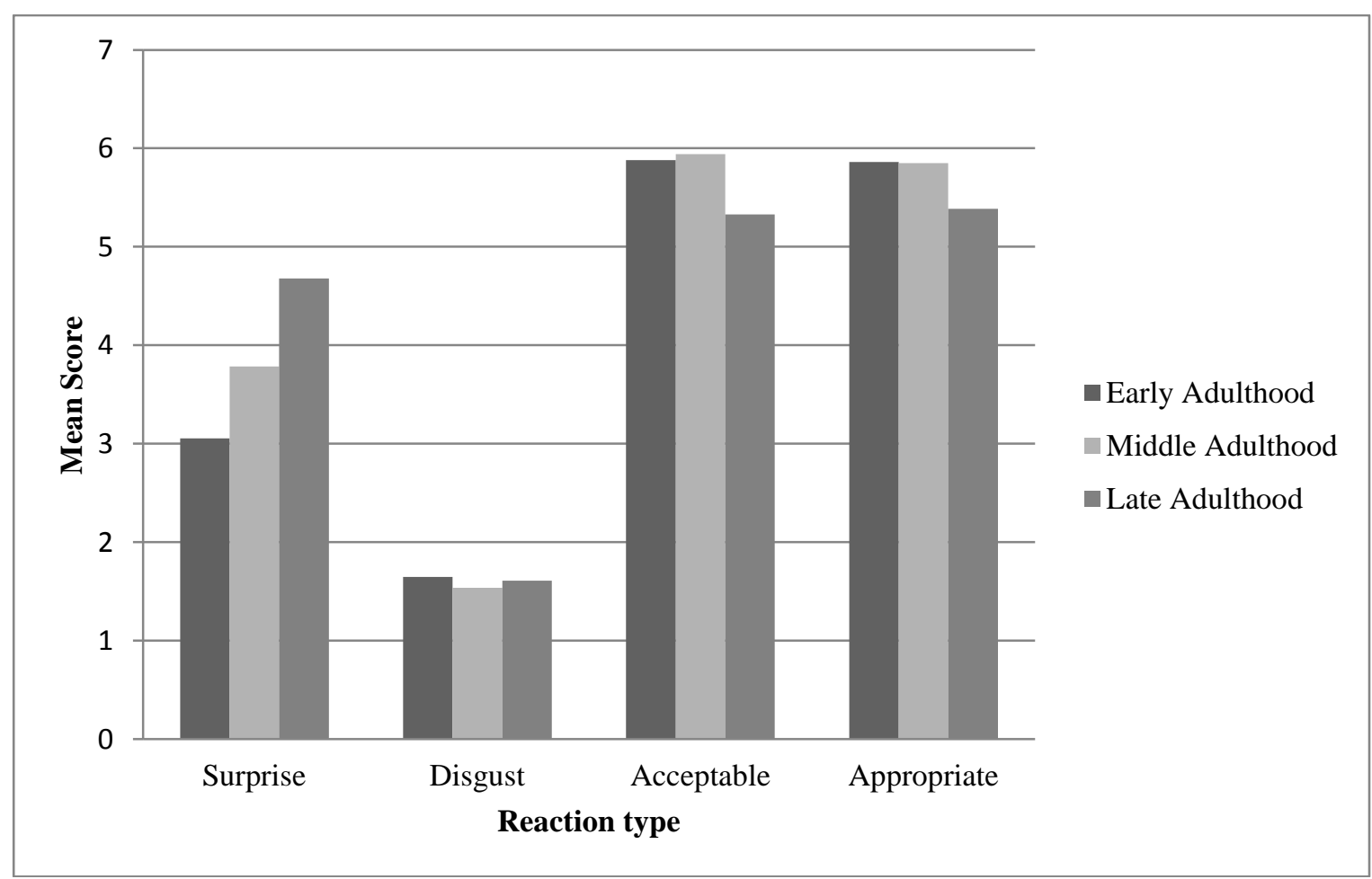




\section{Discussion}

The present study looked to test for evidence of negative reactions to the sexuality of older people. According to the results, there is clear support for the presence of negative reactions. For sexual scenarios, participants were more surprised and more disgusted by incidents of sexuality of those who were 70-75 than those who were 30-35. They also found the scenarios less acceptable and less appropriate. Clearly, sex for early adults is looked upon much favorably than sex for older people. The results were mixed for the 5055 year old group; it is unclear where they fit in. Means for this group sometimes differed significantly from the young adult means, and sometimes differed from the late adulthood group. However, the means for this group always fell between the other two groups' means, suggesting that there is a pattern in how we see sexuality: the older someone is the more strong the negative reactions and the less accepting we are of sexuality. There were no significant findings for gender in the scenarios with sexuality, suggesting that this sample did not view sexuality differently for men and women.

An important finding for the nonsexual scenarios was that there were no significant results for disgust. That means that the reaction of disgust was solely based on sexuality. Although the nonsexual scenarios were things that seemed unusual for older people (getting a tattoo, hiking, and driving a motorcycle across country), people were not disgusted unless the scenario contained sexual content. There were differences in surprise, with people being more surprised to see older people doing these activities. There were also age differences in how acceptable and appropriate the situations were rated: it was less acceptable and appropriate for older people to engage in these activities.

Interestingly, there were gender differences in the nonsexual scenarios, for the ratings of how acceptable and how appropriate. Participants rated single females doing these activities as significantly less acceptable and appropriate than a couple doing these activities. When looking at the scenarios, two stand out as being very independent activities: hiking and driving a motorcycle across the country. It is possible that participants found these activities to be unusual, or possibly even dangerous, for a female to do alone. If that is the reasoning, we see gender stereotypes presenting themselves in the research. For further research, this area could be expanded by testing what activities people see as unacceptable or inappropriate for females that they do not see as such for couples.

There are several limitations in this study that could be remedied by further research. This study covered only two emotions, and two other reactions. There must be many other ways to test the reactions of people to incidents of sexuality, including a broader range of emotions. Also, this study was based on self-report, and participants were asked to imagine the situation. We cannot know how people who react until they were actually in that situation, and we cannot tell how their reaction would affect their behavior. Lastly, the sample in this study was fairly limited: the ages were only 17-21, and the sample was primarily middle-class, college educated, and Caucasian. A more diverse sample would be favorable to generalize the results to American society, particularly in regards to the age group. It would be interesting to see how people of all ages react to these scenarios, particularly people in late adulthood. If a sample of older adults yielded similar results for this study, there would be evidence for internalization of ageist stereotypes. Internalization of this ageism could be a major inhibitor to the continuation of a healthy sex life as aging occurs.

\section{References}

Deacon, S., Minichiello, V., \& Plummer, D. (1995). Sexuality and Older People: Revisiting the Assumptions. Educational Gerontology, 21, 497-513.

DeLamater, J.D., \& Sill, M. (2005). Sexual Desire in Later Life. The Journal of Sex Research, 42(2), 138-149. Retrieved from Jstor database (3813150).

Hall, A., Selby, J., \& Vanclay, F. M. (1982). Sexual Ageism. Australian Journal on Ageing, 1(3), 29-34.

Hillier, S. M., \& Barrow G. M. (2007). Aging, The Individual, And Society. Belmont, CA: Thomas Wadsworth.

Hodson, D. S., \& Skeen, P. (1994). Sexuality and Aging: The Hammerlock of Myths. The Journal of Applied Gerontology, 13(2), 219-235.

Kaplan, H. (1990). Sex, Intimacy, and the Aging Process. Journal of The American Academy of Psychoanalysis, 18(2), 185-205.

Kontula, O., \& Haavio-Mannila, E. (2009). The Impact of Aging on Human Sexual Activity and Sexual Desire. Journal of Sex Research, 46(1), 46-56.

Lai, Y. (2011). A Tale of Two Standards: An Examination of Young Adults' Endorsement of Gendered and Ageist Sexual Double Standards. Sex Roles, 64(5-6), 360-371.

LaTorre, R. (1977). Attitudes Toward Sex in the Age. Archives of Sexual Behavior, 6(3), 203-213.

Pratt, C. C., \& Schmall, V. L. (1989). College Students' Attitudes toward Elderly Sexual Behavior: Implications for Family Life Education. Family Relations, 38(2), 137-141.

White, C. B. (1982). A Scale for the assessment of attitudes and knowledge regarding sexuality in the aged. Archives of Sexual Behavior, 11(6), 491-502. 